\title{
Tibial Spine Avulsion Fractures in Adult: Diagnostic and Therapeutic Actuality
}

\author{
A Zaizi ${ }^{1 *}$, A El Bahraouy ${ }^{1}, N$ Bensiamar ${ }^{1}$, I Aissa ${ }^{2}$, J Boukhris ${ }^{1}, B$ Chafry ${ }^{1}$, D Benchebba ${ }^{1}$, S Bouabid $^{1}$ and \\ M Boussouga ${ }^{1}$
}

${ }^{1}$ Department of Orthopaedic Surgery \& Traumatology II, Mohamed V Military Hospital, Faculty of Medicine and Pharmacy, Mohamed V University, Morocco

${ }^{2}$ Department of Anesthesiology and Reanimation, Mohamed V Military Hospital, Faculty of Medicine and Pharmacy, Mohamed V University, Morocco

\begin{abstract}
Tibial spine fractures are rare lesions which usually occur in adolescent but rare in adults it leads to discontinuity of anterior cruciate ligament. It has been the subject of several publications concerning its anatomopathological presentation and its treatment. The Meyers and Mac Keever classification, modified by Zaricznyj, are the most used and allowed to classify the lesions into 4 types. The treatment of displaced fractures requires surgical reduction and fixation in order to achieve adequate tension in the anterior cruciate ligament and to reduce the risk of laxity, in order to better check the integrity of the anterior cruciate ligament and to guarantee a good stability of the knee and to reduce the risk of laxity, several fixation techniques are described ranging from racking and screwing to osteosuture, currently the surgical reduction can be performed under arthroscopy with the same basic principles of osteosynthesis as arthrotomy but with more advantage and innovative and attractive techniques.
\end{abstract}

Keywords

Tibial spines, ACL, Osteosuture, Arthroscopy

\section{Introduction}

The avulsion fracture of tibial spines is classically common in adolescents, but is more and more common in adults and is reputed to be a sports accident (football or skiing) or road accident $[1,2]$. The radiological classification of Meyers and Mac Keever is modified by a license of repair of the lesions into 4 types. If type I and II are associated with orthopedic treatment, other types are surgical open reduction or arthroscopic reduction with solid osteosynthesis [3].

The main complication of these fractures is a no consolidation or nonunion and knee instability. The objective of this study is to review the different fixation technique of this fracture and compare their results.

\section{Clinical and Radiological Assessment}

The clinical presentation of this trauma is that of a painful knee with functional impotence that can be partial or total. Standard imaging includes radiographs of the traumatized front and profile knee, and it is mainly the lateral radiographs that are particularly useful for assessing the degree of displacement and the type of fracture (Figure 1).

Computed tomography (CT) is interesting to better as- sess the fracture and the degree of communication. MRI, on the other hand, is useful for describing concomitant nonbone lesions such as meniscal, cartilaginous or ligamentous lesions [2].

\section{Classification}

The most commonly used radiographic classification is that of Meyers and Mc Keever, and includes three types depending on the displacement of the bone fragment [3]. It was modified by Zaricznyj who described a fourth type when avulsion is comminutive [4]. Zifko B and Gaudernak T added subtypes to the Meyers classification according to fragment size (Figure 2): Stage A for small fragments and stage B for

*Corresponding author: Abderrahim Zaizi, Resident at Department of Orthopaedic Surgery \& Traumatology II, Mohamed V Military Hospital, Faculty of Medicine and pharmacy, Mohamed V University, Rabat 10100, Morocco, Tel: +212671700824

Accepted: September 05, 2019

Published online: September 07, 2019

Citation: Zaizi A, El Bahraouy A, Bensiamar N, et al. (2019) Tibial Spine Avulsion Fractures in Adult: Diagnostic and Therapeutic Actuality. Arch Sports Med 3(2):169-171 


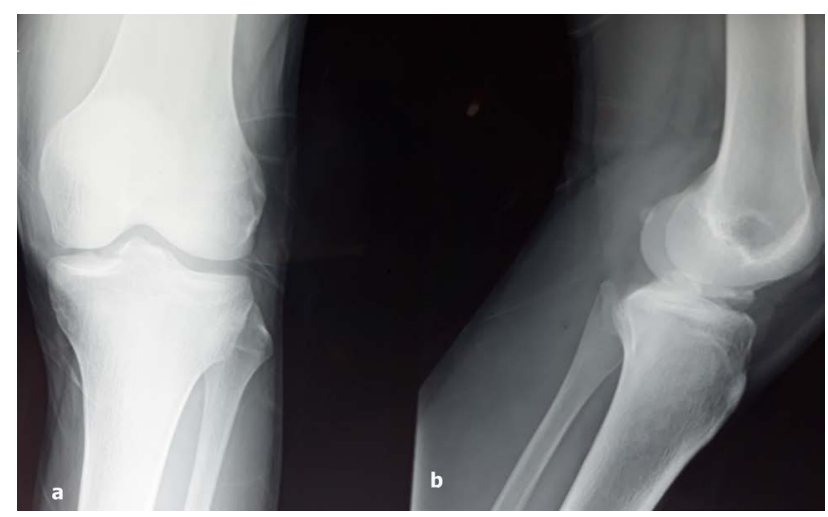

Figure 1: a) Antero-posterior; b) and lateral knee radiographs showing avulsion fracture of tibial spine type III A.
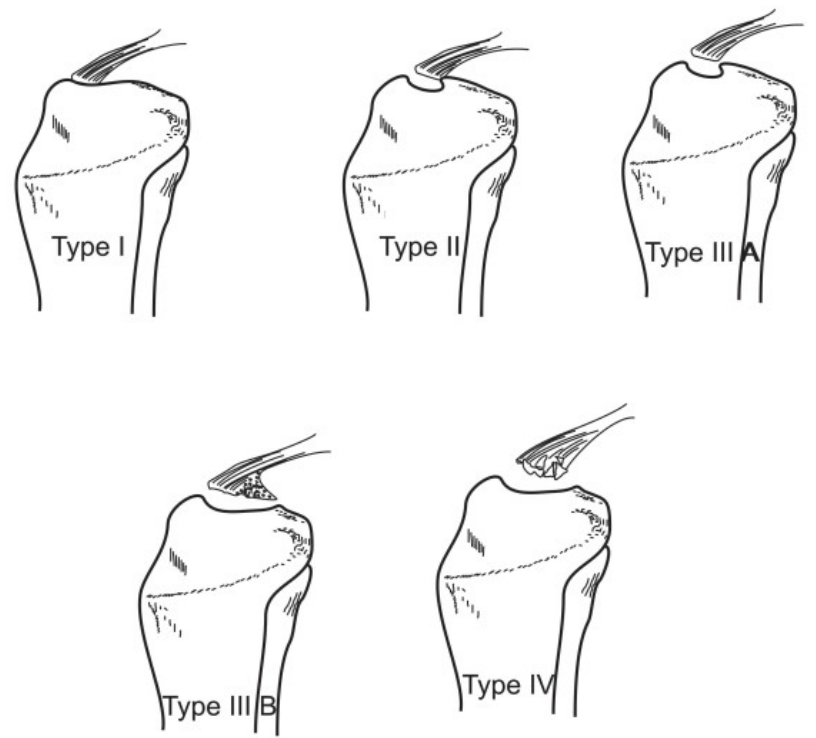

Figure 2: Zariczynj-modified Mayer and Mc Keevers classification of avulsion fractures of tibial spines.

large fragments. Four types are thus described and subdivided into subtypes $A$ or $B$ depending on the displacement of the fragment:

-Type I corresponds to a fracture without displacement.

-Type II results in an anterior uprising of the spine in "duckbill" with continuity of the posterior massif.

-Type III is characterized by a complete lifting of the fragment with a solution of continuity and sometimes a rotation thereof.

-Type IV corresponds to a comminutive fragment.

\section{Treatment}

The management of avulsion fractures of the tibial spines in adults is not consensual: It depends on the type of fracture, the trapping of soft tissues, the associated lesions, but also the surgeon's experience; Type I is treated with plaster immobilization for a period of 4 to 6 weeks, type II treatment is still controversial, while types III and IV are treated

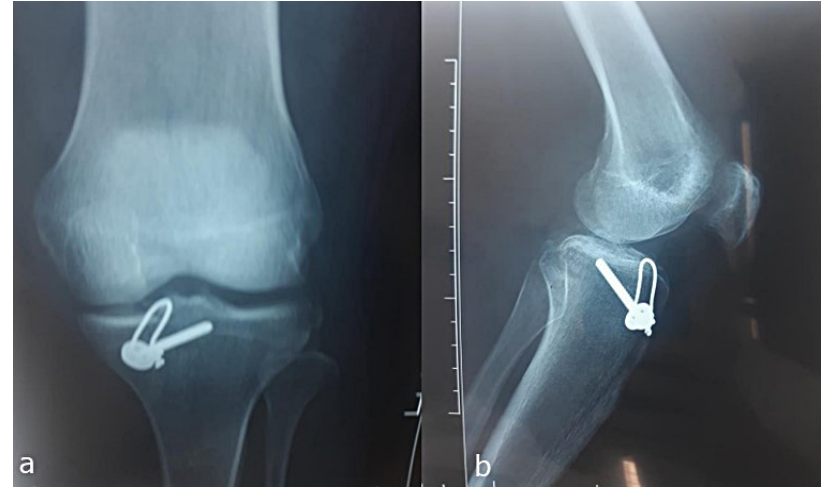

Figure 3: Post-operative $\mathrm{X}$-rays showing an avulsion fracture of the tibial spines treated by lacing with steel wire.

surgically with anatomical reduction and solid osteosynthesis to provide ligament cross an adequate tension (Figure 3).

The principles of the surgical treatment are an anatomical education of the displaced fragment and the good tension of the $A C L$, a rigid and stable fixation allowing a fast rehabilitation, a complete extension of the knee by removing the conflict due to the displaced fragments and finally avoiding the cartilaginous or meniscales lesions thus limiting the degradation of the joint.

Treatment can be performed by open reduction internal fixation (ORIF) through a parapellar arthrotomy or more and more fashionable by arthroscopy that has the advantage of treating tibial spine fracture, meniscal and ligament lesions without being aggressive and allowing a rapid recovery.

After surgical treatment, the limb is protected with a knee plaster brace for 6 weeks. In case of orthopedic treatment rehabilitation is started generally after 6 to 8 weeks of immobilization, but after surgical treatment it is started precociously at 4 weeks [5].

\section{Discussion}

Avulsion fractures of the tibial spines are rare lesions in adults, but most common in adolescents because of the relative weakness of the partially ossified tibial eminence compared to solid fibers of the anterior cruciate ligament. They result from direct or indirect trauma by deceleration mechanism following a sports accident (football or skiing) or an accident on public roads [6].

Poncet was the first to describe these types of fractures in 1895 and it was not until 1959 that Meyers and McKeever established a radiological classification of these lesions.

Type 1 and displaced types 2 are treated orthopedically, while displaced types 2 and types 3 and 4 are treated surgically, there are several techniques of reinsertion of tibial spines described in the literature, Zaricznyj described the fixation by racking in 1977, then Caspari and collaborators described the screwing under arthroscopic control in 1980, Bonin, et al. described the bunching bent in 2006, and recently Hardy described in 2017 a technique of suture by double rank or "Speed Bridge" [7-9]. 
Several comparative biomechanical studies between the different fixation methods have been made, the results of which are very controversial. Seon and Park [10] have carried out a comparative clinical study between fixation by screwing and fixation by suture which concluded that it was there is no significant clinical difference in terms of clinical outcome and stability, whereas Tsukada, et al. [11] observed significant prior translation in suture-treated fractures compared to screw-retained fractures, and the biomechanical study of Bong, et al. [12] concluded that osteosuture was significantly stronger than screwing, Yudong Gan, et al., for his part, conducted a comparative study between four fasteners; lacing with steel wire, osteosuture with non-resorbable wire type PDS, screwing and lastly the guying tensioning (tension band wire fixation) which demonstrated the superiority of the technique of racking guying during cycling tests followed by lacing by steel wire then screwing and finally osteosuture by PDS wire [13].

Other rare studies have found no significant difference in the type of fixation. Fixation by screw is a risk and risk of breaking the fracture fragment and dilacerating the $A C L$ fibers, on the other hand is not often possible if the fragment is communitive, several fixation points are then required by osteosuture by technique bridge or double-row suture originally described for arthroscopic rotator cuff repair.

Fractures of the tibial spines have an excellent prognosis; however, complications can arise, namely joint stiffness and permanent loss of full extension following prolonged immobilization or prominence of current material with a fixation device. In addition to this, non-union or non-union is estimated at $1 \%$, and residual laxity is common, fortunately patients are clinically asymptomatic [14].

In view of all the foregoing we consider that apart from type I, it is arguable to advocate surgical treatment for other types in order to restore good tone to the cruciate ligament. Several surgical techniques are available to surgeons, we think that the best is the one we master.

\section{Conclusion}

The fracture avulsion of the tibial spines is a rare lesion in adults; they pose a problem of therapeutic choice, given the multitude of fixation techniques. They are generally of good prognosis if the care is fast and the reduction is anatomical and stable followed by a re-education adapted allowing a resumption of all the sporting activities.

\section{References}

1. Kendall NS, Hsu SYC, Chan KM (1992) Fracture of the tibial spine in adults and children. A review of 31 cases. J Bone Joint Surg Br 74: 848-852.

2. Oohashi Y (2001) A simple technique for arthroscopic suture fixation of displaced fracture of the intercondylar eminence of the tibia using folded surgical steels. Arthroscopy 17: 1007-1011.

3. Meyers MH, Mckeever FM (1959) Fracture of the intercondylar eminence of the tibia. J Bone Joint Surg Am 41-A: 209-220.

4. Zaricznyj B (1977) Avulsion fracture of the tibial eminence: Treatment by open reduction and pinning. J Bone Joint Surg Am 59: 1111-1114.

5. Davis EM, McLaren MI (2001) Type III tibial spine avulsions treated with arthroscopic Acutrak screw reattachment. Clin Orthop Relat Res, 205-208.

6. Ahn JH, Yoo JC (2005) Clinical outcome of arthroscopic reduction and suture for displace acute and chronic tibial spinefractures. Knee Surg Sports Traumatol Arthrosc 13: 116-121.

7. McLennan JG (1982) The role of arthroscopic surgery in the treatment of fractures of the intercondylar eminence of the tibia. J Bone Joint Surg Br 64: 477-480.

8. Bonin N, Jeunet L, Obert L, et al. (2007) Adult tibial eminence fracture fixation: Arthroscopic procedure using K-wire folded fixation. Knee Surg Sports Traumatol Arthrosc 15: 857-862.

9. A Hardy, L Casabianca, O Grimaud, et al. (2017) Réinsertion arthroscopique type "Speed Bridge » d'une fracture du massif des épines tibiales (complément de la technique par bouton réglable). Revue de chirurgie orthopédique et traumatologique 103: 88-91.

10. Seon JK, Park SJ, Lee KB, et al. (2009) A clinical comparison of screw and suture fixation of anterior cruciate ligament tibial avulsion fractures. Am J Sports Med 37: 2334-2339.

11. Tsukada H, Ishibashi Y, Tsuda E, et al. (2005) A biomechanical comparison of repair techniques for anterior cruciate ligament tibial avulsion fracture under cyclic loading. Arthroscopy 21: 1197-1201.

12. Bong, M, Romero, A, Kubiak, E, et al. (2005) Suture versus screw fixation of displaced tibial eminence fractures: A biomechanical comparison. Arthroscopy 21: 1172-1176.

13. Gan Y, Xu D, Ding J, et al. (2012) Tension band wire fixation for anterior cruciate ligament avulsion fracture: Biomechanical comparison of four fixation techniques. Knee Surg Sports Traumatol Arthrosc 20: 909-915.

14. Van Loon T, Marti RK (1991) A fracture of the intercondylar eminence of the tibial treated by arthroscopic fixation. Arthroscopy 7: 385-388.

DOI: $10.36959 / 987 / 246$

Copyright: (C) 2019 Zaizi A, et al. This is an open-access article distributed under the terms of the Creative Commons Attribution License, which permits unrestricted use, distribution, and reproduction in any medium, provided the original author and source are credited. 